\title{
BMJ open Mortality risks in relation to occupational category and position among the Japanese working population: the Jichi Medical School (JMS) cohort study
}

\author{
Kumi Hirokawa, ${ }^{1}$ Akizumi Tsutsumi, ${ }^{2}$ Kazunori Kayaba, ${ }^{3}$ \\ the Jichi Medical Cohort study group
}

To cite: Hirokawa $\mathrm{K}$, Tsutsumi A, Kayaba K, et al. Mortality risks in relation to occupational category and position among the Japanese working population: the Jichi Medical School (JMS) cohort study. BMJ Open 2013;3: e002690. doi:10.1136/ bmjopen-2013-002690

- Prepublication history for this paper is available online. To view these files please visit the journal online (http://dx.doi.org/10.1136/ bmjopen-2013-002690).

Received 6 February 2013 Revised 1 July 2013 Accepted 3 July 2013
${ }^{1}$ Department of Nursing, Baika Women's University, Ibaraki, Osaka, Japan ${ }^{2}$ Department of Public Health, Kitasato University School of Medicine, Sagamihara, Kanagawa, Japan ${ }^{3}$ Saitama Prefectural University, Koshigaya, Saitama, Japan

Correspondence to Dr Kumi Hirokawa; k-umi@umin.ac.jp

\section{ABSTRACT}

Objectives: A well-known demographic finding in modern society is the inverse association between socioeconomic status and mortality. The purpose of the study was to examine socioeconomic indicators, such as occupational category (white-collar vs blue -collar) and occupational position (managerial vs nonmanagerial) as determinants of all -cause, cardiovascular disease (CVD) and cancer mortality in a Japanese working population.

Design: This is a prospective study.

Participants: Data of a baseline survey were collected between 1992 and 1995, and ultimately 6929 Japanese workers aged 65 years and younger (3333 men and 3596 women) from 12 rural communities across Japan were followed until the end of 2005 .

Main outcome measures: The HRs of death and $95 \% \mathrm{Cls}$ from all causes were calculated using the Cox proportional hazard model.

Results: Men in blue-collar jobs showed an increased all-cause mortality risk compared with those in whitecollar jobs (HR 1.64, 95\% Cl 1.10 to 2.45). Stratified by occupational category, non-managerial women in blue-collar jobs showed a decreased CVD mortality risk compared with managerial women (HR $0.15,95 \% \mathrm{Cl}$ 0.03 to 0.81 ), after adjusting for confounding factors. However, non-managerial women in white-collar jobs showed an increased mortality risk compared with managerial women, although this was not significant (HR 2.34, 95\% Cl 0.25 to 21.87).

Conclusions: Socioeconomic disparity according to occupational category was related to the risk of allcause mortality among Japanese men. There is a potential interaction of occupational category and position in CVD mortality among Japanese women.

\section{INTRODUCTION}

A reproducible demographic finding in modern society is the inverse association between socioeconomic status and mortality. ${ }^{1}$

\section{ARTICLE SUMMARY}

Article focus

- A potential interactional effect of occupational category and position on mortality was examined in a Japanese working population.

Key message

- Socioeconomic disparity according to occupational category was related to mortality risk among Japanese men. There was a potential interaction of occupational category and position in CVD mortality among Japanese women.

Strengths and limitations of this study

- This study is a large-scale prospective cohort study with a Japanese working population and the mean follow-up was more than 10 years. The study sample was not fully representative of the Japanese working population. Job switching was not considered.

Several different indicators of socioeconomic status have been investigated, and educational attainment, employment and income are among the most powerful components of socioeconomic status. ${ }^{3}$ A low occupational socioeconomic status is reportedly associated with increased risks of cancer, ${ }^{4}$ cardiovascular disease $(\mathrm{CVD})^{5}$ and all-cause mortalities compared with a higher occupational socioeconomic status among both men and women in Western countries. ${ }^{56}$

In Japan, it appears that a high socioeconomic status as represented by occupational position is not always inversely associated with mortality. A recent study showed a tendency of increasing all-cause and CVD mortality since the late $1990 \mathrm{~s}$ in Japanese men at the management position. ${ }^{7}$ Another study also revealed that all-cause 
mortality between 1970 and 1985 of Japanese men at the management position was lower than that of production-related workers, but their mortality has been increasing since 1990s. ${ }^{8}$ Regarding Japanese women at the management position, all-cause mortality between 1970 and 2005 was also higher than that of women who were production-related workers. ${ }^{8}$

Different pictures may emerge according to different socioeconomic indices, such as occupational category (white-collar vs blue-collar) and occupational position. Blue-collar workers are more likely to suffer from injuries than are white-collar workers ${ }^{9}{ }^{10}$ and have higher GVD risks than those of white-collar workers. ${ }^{9} 11$ However, the association between occupational category and mortality has been less elucidated in Japanese working populations, prospectively. Furthermore, occupational position appears to have different associations with CVD risk between white-collar and blue-collar occupations. Specifically, among women in white-collar jobs, those in a non-management position showed higher levels of fibrinogen than those in a management position, but there was no such difference among women in blue-collar jobs. ${ }^{12}$

There are sex differences in the effect of socioeconomic factors on health. ${ }^{13}$ Honjo et $a l^{14}$ found associations between occupational category and risk of stroke incidence among Japanese working women, but not among Japanese working men. Another study reported that Japanese blue-collar men perceived themselves to have poor health and physical functioning compared with white-collar men; however, socioeconomic differences in perceived health status were small among Japanese women. $^{15}$

Using a large-scale prospective study (Jichi Medical School (JMS) Cohort Study), we aimed to test as follows: (1) whether a lower occupational category (bluecollar) is associated with increased mortality risk (allcause and cause-specific) compared with a higher occupational category (white-collar), (2) whether a lower occupational position (non-manager) is associated with increased mortality risk compared with a higher occupational position (manager) and (3) whether there is a potential interactional effect of occupational category and position on mortality. Considering the sex differences in social functioning, we analysed women and men separately.

\section{METHODS}

\section{JMS Cohort Study}

The JMS cohort study was a community-based study on CVDs in Japan, initiated in 1992. Data of the baseline survey were collected between 1992 and 1995. Ultimately 12490 Japanese (4911 men and 7579 women) from 12 communities across Japan participated. ${ }^{16}$

The Health and Medical Service Law for the Aged of 1983 requires municipal governments to manage an efficient mass screening examination programme concerned with the risk factors for CVD. The target participants varied from community to community. In some communities, all residents were included, while in others, only those who were not offered health checkups at their workplace or elsewhere were included, such as recipients of Japan's National Health Insurance System who did not join an employees' insurance scheme and were, for example, self-employed persons, homemakers and unemployed persons. Residents aged 40-69 years were invited to participate in a mass screening examination conducted in 8 of the 12 communities. Of the remaining four communities, one community invited those aged 35 years and older to participate and the other three invited adults in other age groups, that is, 39 and younger, 70 and older as well. This resulted in people other than those in the above-defined age groups also being included in the database. The overall response rate was $65.4 \%$. Each prospective candidate signed a consent form to participate in the study.

\section{Participants}

Among the participants of the JMS cohort study, the target population was an active working population aged 65 years and younger. The responses of 2804 men and 2949 women were included in our analyses. Respondents who reported a history of cancer (14 men and 33 women), ischaemic heart diseases (65 men and 34 women) and stroke (23 men and 15 women) were excluded from our analyses. Non-respondents in terms of occupation (402 men and 510 women) and unemployed persons (599 men and 2959 women) were also excluded from our analyses.

Using National Statistics Guidelines, the participants were asked about their current occupation by having the individual select one of the following: farming or forestry, fishery, security, transportation or communication, craft worker or labourer, professional or technician, clerk, sales worker, service worker, homemaker, retired and unclassified. The first five occupations, from farming or forestry to craft worker or labourer, were designated as blue-collar jobs and the next four categories from professional or technician to service worker were designated as white-collar jobs. Participants who were homemakers or had unclassified jobs were excluded from the analyses.

The participants were also asked whether they were an employer (including self-employed business owner) or a manager at their company. Participants (1513 men and 923 women) were classified as management positions if they reported that they were employers or managers at their companies, irrespective of their occupations. The management positions included rather large numbers of employers (1311 men and 864 women), reflecting the rural setting of our study; the majority of them were therefore considered to be self-employed. Ratios of managers to employers were approximately 2-8 for women and 6-4 for men. We decided to include self-employed workers, who may not necessarily have subordinates, as a 
higher occupational status and termed them as managerial, according to several preceding studies. ${ }^{9} \quad 12 \quad 17$ Although our occupational factors were based on simple questions, previous analyses in this cohort showed that the two indices demonstrated a reasonable association with psychosocial job characteristics and health indices. $^{12} 18$ Table 1 shows the participants' occupational distribution in this study.

Mortality data from the date of entry to 31 December 2005 were collected from the Cause-of-Death Register at public health centres in each community with permission from the Agency of General Affairs and the Ministry of Health, Labour and Welfare. Information on the cause of death was coded for the deceased participants using the 10th revision of the International Classification of Diseases (CVD ICD-10 codes: I01-I15, I20-I25, I27, I30-I52, I60-I69 and I99; cancer ICD-10 codes: C00-C16, C18-C20, C22-C34, C43-C97 and D00-D48) with permission from the Agency of General Affairs and the Ministry of Health, Labour and Welfare. Participants who moved out of the communities during the observation period remained in the study until the date of their emigration $(n=369,3 \%)$. The mean follow-up was 12.1 years.

\section{Measurements}

A self-administered questionnaire asked about information on sociodemographic characteristics, including age, sex, marital status, alcohol consumption, smoking status and other lifestyle factors described below. Age at the completion of education was obtained to determine the educational level. The educational levels were categorised as 1 for low education ( $\leq 15$ years) and 0 for high education ( $\geq 16$ years). Marital status was ascertained by asking whether participants were currently married ( 0 as married and 1 as not married). For smoking status, participants were asked whether they were a non-smoker, a former smoker or a current smoker. Alcohol consumption ( $\mathrm{g} /$ day) was estimated by asking how many alcoholic beverages were consumed per day, including Japanese Sake, distilled spirits, whisky (double), beer (bottle), wine (glass) and others. The physical activity index, which was developed in the Framingham Study, ${ }^{19}$ was calculated by totalling the hours at each level of activity and multiplying this by a weight based on the oxygen consumption required for that activity.

A health checkup was given in each community after administration of the questionnaire. Height and weight were measured, and body mass index (BMI) was calculated as weight $(\mathrm{kg}) /$ height $(\mathrm{m})^{2}$. Systolic and diastolic blood pressures were also measured to classify participants as hypertensive: systolic blood pressure $\geq 160 \mathrm{~mm} \mathrm{Hg}$ and diastolic blood pressure $\geq 90 \mathrm{~mm} \mathrm{Hg}$. Patients were also classified as hypertensive if shown by a clinical diagnosis based on medical history information obtained by the questionnaire (ie, currently being treated, have been treated in the past or never treated).
Participants were categorised as not hypertensive (dummy variable of 0 ) or hypertensive (including past and currently treated; dummy variable of 1). For menopausal status, participants were asked whether they were premenopausal (dummy variable of 0 ) or postmenopausal (dummy variable of 1 ).

\section{Statistical analyses}

A $\chi^{2}$ statistic was used to compare the categorical variables among managers who were white-collar, nonmanagers who were white-collar, managers who were blue-collar and non-managers who were blue-collar workers by sex. An analysis of variance (ANOVA) was performed to compare continuous variables among the four groups.

The HRs of death and 95\% CIs from all-causes, CVD and cancer mortality according to occupational category and occupational position were calculated using the Cox proportional hazard model. The HRs and 95\% CIs were calculated again to investigate an interaction of occupational category and occupational position on mortality with adjustment for confounding factors. Occupational category and position, as well as a multiplicative variable of these two occupational factors, were included in the models, with adjustment for covariates. The HRs and 95\% CIs according to occupational position stratified by occupational category were also calculated to investigate a potential interaction of occupational category and occupational position. Age was always included in the models as a covariate. The potential confounding effects of marital status, educational attainment, alcohol consumption, smoking status, the physical activity index, BMI and hypertension were taken into account in the analyses. For women, menopausal status was also included in the model. All statistical analyses were performed with the computer program SPSS V.16.

\section{RESULTS}

The participants' characteristics are shown in table 1. Men and women in blue-collar jobs were older and more physically active than white-collar workers (ANOVA, $\mathrm{p}<0.001$ ). Men and women in blue-collar jobs showed lower percentages of high educational attainment compared with those in white-collar jobs according to $\chi^{2}$ tests $($ all $\mathrm{p}<0.001)$. Women in blue-collar jobs consumed less alcohol (ANOVA, $\mathrm{p}<0.001$ ), and a higher percentage were married $\left(\chi^{2}, \mathrm{p}<0.001\right)$, non-smokers $\left(\chi^{2}, \mathrm{p}=0.001\right)$ and menopausal $\left(\chi^{2}, \mathrm{p}<0.001\right)$ than those in white-collar jobs. Among women in white-collar jobs, managers also showed a higher BMI than that of nonmanagers (ANOVA, $\mathrm{p}=0.001$ ). Among men in whitecollar jobs, managers showed a higher BMI and consumed more alcohol compared with non-managers (BMI: ANOVA, $\mathrm{p}<0.001$; alcohol: ANOVA, $\mathrm{p}=0.04$ ). Among men in white-collar and blue-collar jobs, managers showed a lower percentage of being unmarried than did non-managers $\left(\chi^{2}, \mathrm{p}<0.001\right)$. 
Table 1 Participants' demographic data

\begin{tabular}{|c|c|c|c|c|c|c|c|c|}
\hline \multirow[b]{3}{*}{ Number } & \multicolumn{4}{|l|}{ Men } & \multicolumn{4}{|l|}{ Women } \\
\hline & \multicolumn{2}{|l|}{ White-collar } & \multicolumn{2}{|l|}{ Blue-collar } & \multicolumn{2}{|l|}{ White-collar } & \multicolumn{2}{|l|}{ Blue-collar } \\
\hline & $\begin{array}{l}\text { Manager } \\
549\end{array}$ & $\begin{array}{l}\text { Non-manager } \\
305\end{array}$ & $\begin{array}{l}\text { Managers } \\
985 \\
\end{array}$ & $\begin{array}{l}\text { Non-managers } \\
965\end{array}$ & $\begin{array}{l}\text { Managers } \\
549 \\
\end{array}$ & $\begin{array}{l}\text { Non-managers } \\
876\end{array}$ & $\begin{array}{l}\text { Managers } \\
380\end{array}$ & $\begin{array}{l}\text { Non-managers } \\
1144\end{array}$ \\
\hline Professionals/technicians (\%) & 19.1 & 28.5 & & & 10.4 & 16.0 & & \\
\hline Clerks (\%) & 20.4 & 26.2 & & & 21.5 & 24.7 & & \\
\hline Sales workers (\%) & 33.3 & 16.1 & & & 31.5 & 19.1 & & \\
\hline Service workers (\%) & 27.1 & 29.2 & & & 36.6 & 40.3 & & \\
\hline Farming or Forestry (\%) & & & 38.2 & 36.5 & & & 48.9 & 51.4 \\
\hline Fishery (\%) & & & 13.0 & 9.6 & & & 1.8 & 2.4 \\
\hline Security (\%) & & & 0.1 & 1.6 & & & 0.3 & 0.0 \\
\hline Transportation/communication (\%) & & & 4.0 & 5.0 & & & 0.5 & 0.2 \\
\hline Craft workers/labours (\%) & & & 44.7 & 47.4 & & & 48.4 & 46.1 \\
\hline Age (SD) & $49.1^{\mathrm{b}}(8.9)$ & $44.5^{\mathrm{b}}(11.2)$ & $51.4^{\mathrm{a}}(9.7)$ & $51.2^{\mathrm{a}}(11.2)$ & $49.6^{\mathrm{b}}(8.4)$ & $46.2^{b}(10.5)$ & $53.0^{\mathrm{a}}(8.2)$ & $52.3^{\mathrm{a}}(8.2)$ \\
\hline Alcohol (g/day, SD) & $52.6^{\mathrm{a}}(62.5)$ & $42.7^{\mathrm{b}}(37.7)$ & $48.2(45.3)$ & $47.1(44.9)$ & $11.6^{\mathrm{a}}(33.6)$ & $10.3^{a}(28.9)$ & $8.1(22.8)$ & $6.1^{\mathrm{b}}(15.3)$ \\
\hline Physical activity(METs, SD) & $31.2^{b}(5.9)$ & $31.3^{\mathrm{b}}(6.9)$ & $39.3^{a}(11.6)$ & $38.8^{a}(10.7)$ & $30.6^{\mathrm{b}}(4.1)$ & $30.1^{\mathrm{b}}(4.3)$ & $34.6^{\mathrm{a}}(7.5)$ & $33.6^{a}(6.9)$ \\
\hline Body mass index (SD) & $23.7^{\mathrm{a}}(2.8)$ & $23.0^{\mathrm{b}}(2.9)$ & $23.2^{b}(2.9)$ & $22.8^{\mathrm{b}}(2.8)$ & $23.3^{\mathrm{a}}(3.1)$ & $22.8^{\mathrm{b}}(3.1)$ & $22.8(2.9)$ & $23.2^{\mathrm{a}}(3.1)$ \\
\hline Married (\%) & $94.0^{\mathrm{a}}$ & $83.9^{\mathrm{b}}$ & $94.9^{\mathrm{a}}$ & $86.1^{\mathrm{b}}$ & 91.4 & $90.0^{\mathrm{b}}$ & 95.5 & $96.0^{\mathrm{a}}$ \\
\hline \multicolumn{9}{|c|}{ Age (years) at termination of education (\%) } \\
\hline$\leq 15$ & $22.3^{b}$ & $20.0^{\mathrm{b}}$ & $44.1^{\mathrm{a}}$ & $51.4^{\mathrm{a}}$ & $29.4^{b}$ & $31.1^{\mathrm{b}}$ & $52.5^{\mathrm{a}}$ & $54.6^{\mathrm{a}}$ \\
\hline$\geq 16$ & $77.7^{\mathrm{a}}$ & $80.0^{a}$ & $55.9^{\mathrm{b}}$ & $48.6^{b}$ & $70.6^{a}$ & $68.9^{a}$ & $47.5^{\mathrm{b}}$ & $45.4^{\mathrm{b}}$ \\
\hline \multicolumn{9}{|l|}{ Smoking status (\%) } \\
\hline Non-smoker & 20.6 & 18.4 & $24.0^{\mathrm{a}}$ & 20.0 & 89.2 & $87.1^{\mathrm{b}}$ & $94.0^{\mathrm{a}}$ & $92.2^{\mathrm{a}}$ \\
\hline Past smoker & $27.1^{a}$ & 24.0 & 22.7 & 23.1 & 2.8 & $3.8^{\mathrm{a}}$ & 1.6 & 2.4 \\
\hline Current smoker & 52.3 & 57.6 & 53.3 & 56.9 & 8.0 & $9.1^{\mathrm{a}}$ & $4.3^{b}$ & $5.4^{b}$ \\
\hline \multicolumn{9}{|l|}{ Hypertension (\%) } \\
\hline No history & 73.9 & 79.9 & 76.2 & 75.5 & 81.6 & 84.5 & 79.9 & 81.3 \\
\hline Past history and under treatment & 26.1 & 20.1 & 23.8 & 24.5 & 18.4 & 15.5 & 20.1 & 18.7 \\
\hline Menopause (\%) & & & & & $49.4^{b}$ & $38.6^{b}$ & $68.3^{\mathrm{a}}$ & $63.9^{\mathrm{a}}$ \\
\hline
\end{tabular}

$\mathrm{a}$ and $\mathrm{b}$ indicate a significant difference between values $(\mathrm{a}>\mathrm{b}, \mathrm{p}<0.05)$, according to a Bonferroni's post hoc test.

$\mathrm{a}$ indicates to be significantly high percentage compared to an expected value and $\mathrm{b}$ indicates to be significantly low percentage compared to an expected value, according to a adjusted

residual.

METs, metabolic equivalents. 
During the follow-up years, the numbers of deaths observed were as follows: death from all causes included 227 men and 95 women, death from CVD included 35 men and 16 women, and death from cancer included 98 men and 53 women. Person-years at risk were 37355 for men and 41264 for women.

Results of a separate investigation of the effects of occupational category and occupational position on mortality by sexes are shown in table 2. Kaplan-Meier survival curves by occupational category and position are shown in figures 1 and 2. Men in blue-collar jobs showed an increased all-cause mortality risk compared with those in white-collar jobs, after adjusting for age (HR 1.54, 95\% CI 1.07 to 2.23). This result was the same after adjusting for confounding factors (HR 1.64, 95\% CI 1.10 to 2.45). Men in blue-collar jobs showed a tendency to have increased mortality risks of CVD and cancer compared with those in white-collar jobs, but this did not reach significance. Although no significant association was found among women, women in blue-collar jobs showed a tendency to have reduced mortality risks compared with those in white-collar jobs.

There was no significant association between occupational position and mortality risks in men. Women in non-management positions showed a tendency to have a reduced mortality risk compared with those in management, but this result did not reach statistical significance.

When the interaction of occupational category and position with mortality was analysed, there was no significant association in men (all-cause: HR 0.98, 95\% CI 0.45 to 2.14; CVD: HR 1.02, 95\% CI 0.10 to 10.25 and cancer: HR $0.77,95 \%$ CI 0.25 to 2.41$)$. On the other hand, the interaction of occupational category and position was associated with a reduced risk of CVD mortality in women (all-cause: HR 0.99, 95\% CI 0.36 to 2.73; CVD: HR $0.06,95 \%$ CI 0.00 to 0.90 and cancer: HR $1.57,95 \%$ CI 0.38 to 6.53$)$.

Results on the association between occupational position and mortality stratified by occupational category are shown in table 3. There was no significant association between occupational position and all-cause, CVD, and cancer mortality among white-collar and blue-collar men. Non-managerial women in blue-collar jobs showed a decreased mortality risk compared with managerial women in blue-collar jobs (HR $0.15,95 \%$ CI 0.03 to 0.81 ), after adjusting for confounding factors. However, non-managerial women in white-collar jobs showed an increased mortality risk compared with those in whitecollar jobs, although this was not significant (HR 2.34, $95 \%$ CI 0.25 to 21.87 ).

\section{DISCUSSION}

The present prospective study revealed that Japanese men in blue-collar jobs showed a higher risk of mortality than those in white-collar jobs. There was no significant association between occupational position and mortality risks both in men and women. Non-managerial women in blue-collar jobs showed a decreased CVD mortality risk compared with managerial women. Non-managerial women in white-collar jobs showed an increased mortality risk compared with managerial women, but this was not statistically significant. These results among women suggest a different function of occupational position between white-collar and blue-collar jobs.

Men in blue-collar jobs had a higher risk of mortality than those in white-collar jobs as reported in Western countries. ${ }^{4-6}{ }^{20}$ Men in white-collar jobs may have several advantages, including income, working conditions, social networks and education levels compared with those in blue-collar jobs. ${ }^{20} 21$ These inequalities could heighten an individual's occupational stress level and maladaptive coping responses (eg, smoking) among men in blue-collar jobs. ${ }^{22}$ Furthermore, inverse socioeconomic gradients have been observed in the occurrence of unintentional injury. ${ }^{10} \quad 23$ Especially in agricultural populations, injuries were extremely important health issues. ${ }^{24}$

Although recent studies in Japan reported that men in management positions have a tendency to increase their mortality, ${ }^{78}$ the present prospective study showed that their mortality risk was not statistically different from that of men in non-management positions. Wada et $a l^{7}$ attributed the observed increases in mortality in male management positions, in particular of suicide, to the radical changes in socioeconomic conditions of the 1990s rather than to inherent characteristics of the work environment in Japan. However, another Japanese study suggested a stronger deteriorating effect of the 1990s economic crisis on self-rated health among nonmanagerial men than among managerial men. ${ }^{25}$ In our study population, the majority of managers were selfemployed in rural areas and thus may have been less likely to suffer from economic crises. Because the aforementioned previous studies used Japanese governmental vital statistic records collected every 5 years, ${ }^{7} 8$ differences in methodology may have also contributed to results that differ from those obtained by direct observation, such as ours.

Occupational position may have different effects on CVD mortality risk between white-collar and blue-collar occupations among Japanese working women. We previously reported that among white-collar women, nonmanagers had higher fibrinogen levels compared with managers. ${ }^{12}$ The results of white-collar women in the present study showed a similar tendency; however, those of blue-collar women were not consistent with the previous study. The interactive effect of occupational category and position on mortality may be dependent on the social and working environments. Associations between socioeconomic status and health are influenced by economic development, culture and historic and generational backgrounds. ${ }^{26} 27$ For example, a traditional attitude towards gender roles, such as the idea that men should go to work while women should stay at home, are 
Table $2 \mathrm{HRs}(95 \% \mathrm{Cl})$ of all cause, all cardiovascular disease (CVD), and all cancer mortality related to occupational category and occupational position

Men

Person-years Certality rate

Deceased 1000 per person-years $(95 \% \mathrm{Cl})$

(n)

(n)

All cause

Occupational category

White-collar 10348

Blue-collar 10348.1

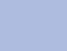

(n)

$\begin{array}{rrrr}830 & 40 & 3.87 & 1\end{array}$

Occupational position

\begin{tabular}{ll} 
Manager $\quad 18529.6$ \\
\hline
\end{tabular}

Non-manager $\quad 14870.4$

$\begin{array}{rrr}830 & 40 & 3.87 \\ 2074 & 187 & 6.92\end{array}$

1.54

$1.54(1.07$ to 2.23$) \quad 1.64(1.10102 .45) \quad 24019.0$

$1427 \quad 107 \quad 12.33$

$\begin{array}{rrr}1180 & 90 & 3.92\end{array}$

1

$1 \quad 1 \quad 11125.9$

0.98 (0.74 to 1.30$) \quad 1.00$ (0.74 to 1.35$) \quad 24352.7$

$\begin{array}{rrrr}863 & 7 & 0.68 & 1\end{array}$

$1 \quad 1 \quad 17245.3$

$\begin{array}{lll}1.58(0.64 \text { to } 3.89) & 1.84 \text { (0.69 to } 4.89) & 24019.0\end{array}$

White-collar 10348.1

Blue-collar 27006.7

Occupational position

Manager $\quad 18529.6$

Non-manager $\quad 14870.4$

1.04

$\begin{array}{lll}1512 & 22 & 2.54\end{array}$

$\begin{array}{lll}1512 & 22 & 2.54 \\ 1260 & 10 & 0.44\end{array}$

1

$1 \quad 1$

1

11125.9

1

$1 \quad 1 \quad 17245.3$

White-collar 10348.1

$\begin{array}{ll}\text { Blue-collar } & 27006.7\end{array}$

Occupational position

\begin{tabular}{ll} 
Manager & 18529.6 \\
\hline
\end{tabular}

$\begin{array}{lll}851 & 19 & 1.84\end{array}$

$\begin{array}{lll}2182 & 79 & 2.93\end{array}$

1.40 (0.80 to 2.45$) \quad 1.37(0.75$ to 2.51$) \quad 24019.0$

$\begin{array}{lll}1 & 1 & 11125.9 \\ 1.07(0.69 \text { to } 1.66) & 1.16(0.73 \text { to } 1.85) & 24352.7\end{array}$

$\begin{array}{ll}1490 & 44 \\ 1230 & 40\end{array}$

5.07
1.74

$\begin{array}{ll}1446 & 18 \\ 1915 & 35 \\ & \\ 914 & 15\end{array}$

$1993 \quad 27$

$\begin{array}{ll}15 & 6.38 \\ 27 & 0.84\end{array}$

0.84

Mortality rate

1000 per

person-years $(95 \% \mathrm{Cl})$

adjusted HR Adjusted HR*

Menopause status was also adjusted for women. 
Figure 1 Kaplan-Meier survival curves of all-cause mortality by occupational category.
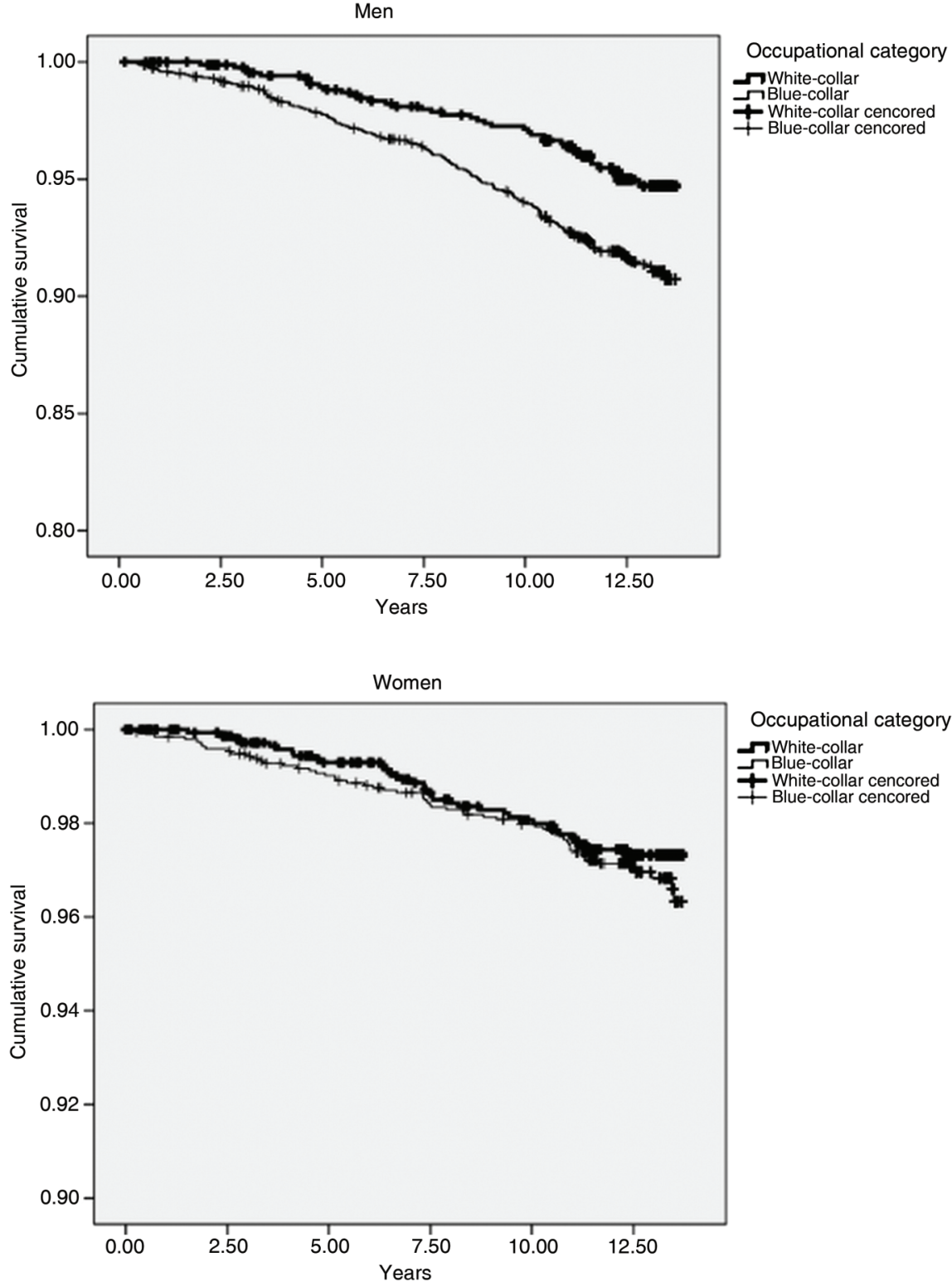

also grounded on cultural and ideological users and meanings that vary with time and geography. ${ }^{27}$ In the case of Japanese women, a small percentage of women was represented in the management position, namely only $8 \%$ of the total managerial positions in $2009^{28}$; however, this figure is expected to increase in the future. The small number of cause-specific deaths in the occupational groups among women needs to be considered when generalising these results because of the insufficient power in these analyses. The effects of occupational positions on health between white-collar and blue-collar occupations should be investigated further in future studies.

A possible reason why there are sex differences in associations between socioeconomic status and health may be due to psychological stress. For example, job stress was associated with an increased all-cause mortality risk in Finnish men in both white-collar and blue-collar jobs, while it was associated with a reduced all-cause mortality risk in women in white-collar jobs. ${ }^{29}$ Although job stress has an effect on incidence risks of stroke in Japanese men and women, its associations with occupational category and position are different in men and women. ${ }^{30}$ The sex differences in associations between socioeconomic indicators and health in the Japanese working population could also be attributed to the work environment, such as a promotion support system for child rearing or care giving at work in Japan. Japanese women encounter large wage differences compared with men, low promotion rates, low access to child-rearing services and high burdens of aged people's care. ${ }^{31}$ Other lifestyle factors for women, such as their husband's socioeconomic status, burdens of child rearing and aged parent's care, rather than the working environment, are also assumed to influence Japanese women's health.

There are several limitations to this study. Although large numbers of workers were included in this study, 
Figure 2 Kaplan-Meier survival curves of all-cause mortality by occupational position.
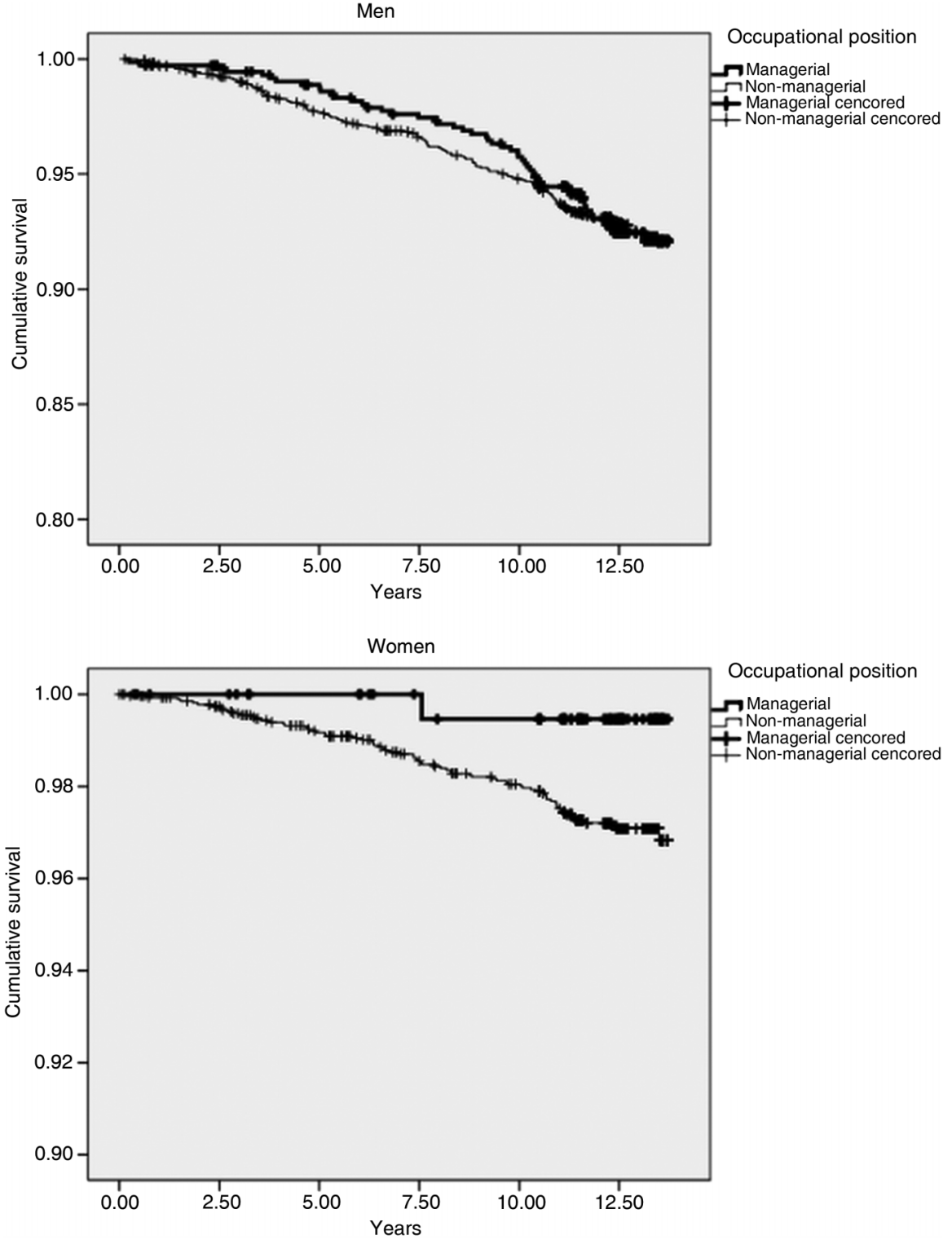

the study sample was not fully representative of the Japanese working population. Proportions of participants in blue-collar jobs, including farmers and forestry labourers, were high compared with preceding studies. ${ }^{78}$ Furthermore, about $30 \%$ of the women were in a management position. It is assumed that many selfemployed persons were possibly included in the present study and they may be subject to different working conditions compared with persons in a managerial position at a large-sized company. These possible differences with the urban population could lead to an underestimation of risk. A larger study sample and a longer follow-up time are required to explore the interactive associations between occupational category and occupational position in each cause-specific analysis in a middle-aged population. Occupational category and position were determined by current employment and job switching was not considered, although changes in occupation or job position are not frequent in the rural settings included in the study. ${ }^{32}$ Unpredictable occupational misclassification may lead to a bias, and such measurement errors are probably undifferentiated and could lead to underestimations of the differences. Income levels and employment patterns, such as full time and part time, were not considered. Further studies with more detailed measurements of occupational hierarchy are required to confirm our findings.

In conclusion, there was an increased risk of all-cause mortality among Japanese male workers engaged in a lower occupational category (blue collar). A potential interactional effect of occupational category and position on CVD mortality was suggested in Japanese working women. As women's promotion to management increases, further investigations are needed to explore the association between occupational position/category and CVD mortality. 
Table 3 HRs $(95 \% \mathrm{Cl})$ of all-cause, all cardiovascular disease (CVD) and all cancer mortality related to occupational position stratified by occupational category White-collar Blue-collar

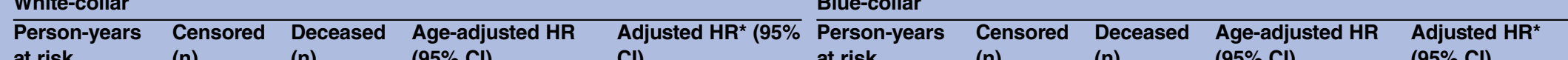


Contributors $\mathrm{KH}$ analysed the data and wrote this manuscript. AT was engaged in manuscript writing, data analyses and also participated in the data collection of the Jichi Medical School (JMS) Cohort Study. KK participated in the JMS Cohort Study as the manager for data collection and also engaged in the conception of the manuscript writing. All authors have read and approved the final version of the manuscript.

Funding This study was partly supported by a Grant-in-Aid from the Foundation for the Development of the Community, Tochigi, Japan, and by a Grant-in-Aid for Scientific Research (C) (No. 19590607). A Grant-in-Aid for Scientific Research on Innovative Areas (Research in a Proposed Research Area) 2010 and 2011 (No. 4102-21119003) from the Ministry of Education, Culture, Sports, Science and Technology, Japan, also supported the present study.

\section{Competing interests None.}

Patient consent Obtained.

Ethics approval The study design and procedures were reviewed and approved by each municipal government and the Ethics Committee for Epidemiological Research at Jichi Medical School.

Provenance and peer review Not commissioned; externally peer reviewed.

Data sharing statement No additional data are available.

Open Access This is an Open Access article distributed in accordance with the Creative Commons Attribution Non Commercial (CC BY-NC 3.0) license which permits others to distribute, remix, adapt, build upon this work noncommercially, and license their derivative works on different terms, provided the original work is properly cited and the use is non-commercial. See: http:// creativecommons.org/licenses/by-nc/3.0/

\section{REFERENCES}

1. Davey Smith G, Carroll D, Rankin S. Socio-economic differentials in mortality: evidence form Glasgow graveyards. BMJ 1992;305:1554-7.

2. Davey Smith G, Hart C, Hole D, et al. Education and occupational social class: which is the more important indicator of mortality risk? $J$ Epidemiol Community Health 1998;52:153-60.

3. Kagamimori S, Gaina A, Nasermoaddeli A. Socioeconomic status and health in the Japanese population. Soc Sci Med 2009;68:2152-60.

4. Bentley R, Kavanagh AM, Subramanian SV, et al. Area disadvantage, individual socio-economic position, and premature cancer mortality in Australia 1998 to 2000: a multilevel analysis. Cancer Causes Control 2008;19:183-93.

5. Pekkanen J, Tuomilehto J, Uutela A, et al. Social class, health behaviour, and mortality among men and women in eastern Finland. BMJ 1995;311:589-93.

6. Turrell G, Kavanagh A, Draper G, et al. Do places affect the probability of death in Australia? A multilevel study of area-level disadvantage, individual-level socioeconomic position and all-cause mortality, 1998-2000. J Epidemiol Community Health 2007;61:13-19.

7. Wada K, Kondo N, Gilmour S, et al. Trends in cause specific mortality across occupations in Japanese men of working age during period of economic stagnation, 1980-2005: retrospective cohort study. BMJ 2012;344:e1191.

8. Suzuki E, Kashima S, Kawachi I, et al. Social and geographic inequalities in premature adult mortality in Japan: a multilevel observational study from 1970 to 2005. BMJ Open 2012;2:e000425.

9. Fukuda $\mathrm{Y}$, Nakamura K, Takano T. Accumulation of health risk behaviours is associated with lower socioeconomic status and women's urban residence: a multilevel analysis in Japan. BMC Public Health 2005;5:53.

10. Roberts I, Power CL. Does the decline in child injury mortality vary by social class? A comparison of class specific mortality in 1981 and 1991. BMJ 1996;313:784-6.
11. Nakamura S, Nakamura K, Tanaka M. Increased risk of coronary heart disease in Japanese blue-collar workers. Occup Med 2000;50:11-17.

12. Hirokawa K, Tsutsumi A, Kayaba K. Occupation and plasma fibrinogen in Japanese male and female workers: the Jichi Medica School cohort study. Soc Sci Med 2009;68:1091-7.

13. Kopp MS, Skrabski A, Székely A, et al. Chronic stress and social changes: socioeconomic determination of chronic stress. Ann NY Acad Sci 2007;1113:325-38.

14. Honjo K, Tsutsumi A, Kayaba K. Jichi Medical School Cohort Study Group. Socioeconomic indicators and cardiovascular disease incidence among Japanese community residents: the Jichi Medical School Cohort Study. Int J Behav Med 2010;17:58-66.

15. Martikainen $\mathrm{P}$, Lahelma $\mathrm{E}$, Marmot $\mathrm{M}$, et al. A comparison of socioeconomic differences in physical functioning and perceived health among male and female employees in Britain, Finland and Japan. Soc Sci Med 2004;59:1287-95

16. Ishikawa S, Gotoh T, Nago N, et al. The Jichi Medical School (JMS) Cohort Study: design, baseline data and standardized mortality ratios. J Epidemiol 2002;12:408-17.

17. Atherton K, Power C. Health inequalities with the National Statistics-Socioeconomic Classification: disease risk factors and health in the 1958 British birth cohort. Eur J Public Health 2007;17:486-91.

18. Tsutsumi A, Kayaba K, Tsutsumi K, et al. Association between job strain and prevalence of hypertension: a cross sectional analysis in a Japanese working population with a wide range of occupations: the Jichi Medical School cohort study. Occup Environ Med 2001;58:367-73.

19. Kennel WB, Sorlie P. Some health benefits of physical activity: the Framingham study. Arch Intern Med 1979;139:857-61.

20. Armstrong DL, Strogatz D, Barnett E, et al. Joint effects of social class and community occupational structure on coronary mortality among black men and white men, upstate New York, 1988-92. $J$ Epidemiol Community Health 2003;57:373-8.

21. Pill R, Peters TJ, Robling MR. Social class and preventive health behaviour: a British example. J Epidemiol Community Health 1995;49:28-32.

22. Wagstaff A, Van Doorslaer E. Income inequality and health: what does the literature tell us? Annu Rev Public Health 2000;21:543-67.

23. Feeney A, North F, Head J, et al. Socioeconomic and sex differentials in reason for sickness absence from the Whitehall II Study. Occup Environ Med 1998;55:91-8.

24. Pickett W, Day AG, Hagel L, et al. Socioeconomic status and injury in a cohort of Saskatchewan farmers. J Rural Health 2011;27:245-54.

25. Kondo N, Subramanian SV, Kawachi I, et al. Economic recession and health inequalities in Japan; analysis with a national sample, 1986-2001. J Epidemiol Community Health 2008;62:869-75.

26. Addo J, Smeeth L, Leon DA. Socioeconomic position and hypertension: a study of urban civil servants in Ghana. J Epidemiol Community Health 2009;63:646-50.

27. Alves L, Azevedo A, Silva S, et al. Socioeconomic inequalities in the prevalence of nine established cardiovascular risk factors in a southern European population. PLOS ONE 2012;7:e37158.

28. Ministry of Health, Labour, and Welfare Heisei 21 nendo koyo kinto kihon chosa. 7. Equal Employment and Child Welfare. In Annual Health, Labour and Welfare Report 2009-2010, 2010:167.

29. Von Bonsdorff MB, Seisamo J, Von Bonsdorff ME, et al. Job strain among blue-collar and white-collar employees as a determinant of total mortality: a 28-year population-based follow-up. BMJ Open 2012;2:e000860.

30. Tsutsumi A, Kayaba K, Ishikawa S. Impact of occupational stress on stroke across occupational classes and genders. Soc Sci Med 2011;72:1652-8.

31. Kawakami N, Haratani T, Kobayashi F, et al. Occupational class and exposure to job stressors among employed men and women in Japan. J Epidemiol 2004;14:204-10.

32. Kayaba K, Tsutsumi A, Gotoh T, et al. Five-year stability of job characteristics scale scores among a Japanese working population. J Epidemiol 2005;15:228-34. 